\title{
Enhanced efficiency of perovskite solar cells through improving active layer morphology by interfacial engineering
}

Perovskite solar cells (pero-SCs), with organic-inorganic hybrid perovskite semiconductors (e.g. $\mathrm{CH}_{3} \mathrm{NH}_{3} \mathrm{PbI}_{3}$ ) as active layer, have become the hottest research field in recent several years due to their distinguished advantages of high power conversion efficiency $(15 \%$ 20\%) and solutionprocessability which is very important for low cost large area production by roll-to-roll technique. To realize the high efficiency, key points are the morphology control of highly crystalline and homogeneous perovskite $\mathrm{CH}_{3} \mathrm{NH}_{3} \mathrm{PbI}_{3}$ active layers and the interfacial engineering between the active layer and two electrodes in the pero-SCs. Many researchers have devoted their efforts on the morphology control by using solvent additives, two-step spin coating, and different lead salts, etc. and on the interfacial engineering by using various cathode buffer layer and anode buffer layer materials. Obviously, it is desirable to develop simple strategy to combine the morphology control and the interfacial engineering together.

A significant progress on this issue was reported recently by Hongzheng Chen's group at Zhejiang University [1]. They developed a facile but efficient method of modifying the $\mathrm{ZnO}$-coated ITO substrates with self-assembling monolayer of 3-aminopropanioc acid (C3-SAM) to direct the crystalline evolution and morphology control of $\mathrm{CH}_{3} \mathrm{NH}_{3}-$ $\mathrm{PbI}_{3}$ perovskite film (Figure 1). With the C3-SAM monolayer on the surface of the substrate, highly crystalline and homogenous $\mathrm{CH}_{3} \mathrm{NH}_{3} \mathrm{PbI}_{3}$ films were formed with reduced pin-holes and trap states density, which is benefitted from the amino group rich surface of C3-SAM monolayer. In addition, the work function of the cathode modified by the C3-SAM monolayer is better aligned with the energy level of the conduction-band bottom of $\mathrm{CH}_{3} \mathrm{NH}_{3} \mathrm{PbI}_{3}$ perovskite for efficient electron collection and transportation. As a result, the interface modification led to more than $30 \%$ increase in the device efficiency with the highest power conversion efficiency of $15.67 \%$ that stands as one of the highest values among the planar pero-SCs with $\mathrm{ZnO}$ as electron transporting layer.

Polymer solar cell is another hot research field in the solution-processable solar cells due to its advantages of light weight and flexibility. The strategy of cathode buffer layer covered with self-assembling monolayer could also play important roles in improving photovoltaic performance of the polymer solar cells.

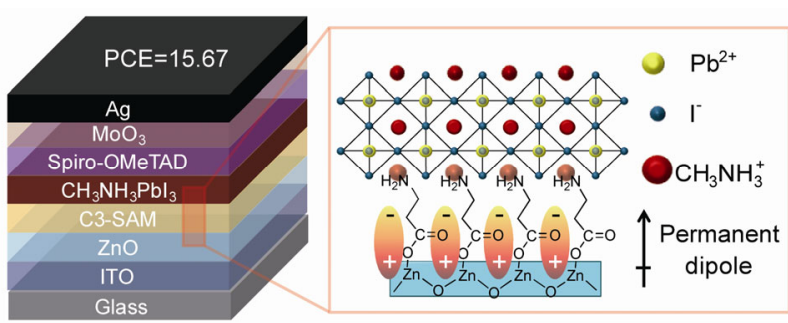

Figure 1 Schematic diagram of device structure and C3-SAM induced dipole moment formation and involvement of the SAM in the crystalline structure of the $\mathrm{CH}_{3} \mathrm{NH}_{3} \mathrm{PbI}_{3}$ film.

Yongfang Li

Institute of Chemistry, Chinese Academy of Sciences

1 Zuo L, Gu Z, Ye T, Fu W, Wu G, Li H, Chen H. Enhanced photovoltaic performance of $\mathrm{CH}_{3} \mathrm{NH}_{3} \mathrm{PbI}_{3}$ perovskite solar cells through interfacial engineering using self-assembling monolayer. $\mathrm{J} \mathrm{Am} \mathrm{Chem}$ Soc, 2015, 137: 2674-2679 